\title{
Interactions among litter chemical traits alter the non-additive effect of litter mixing
}

\author{
hongling yang ${ }^{1}$, Yulin $\mathrm{Li}^{1}$, jin zhan ${ }^{1}$, Chelmeg Bao ${ }^{1}$, yongqing luo ${ }^{1}$, zhiying ning ${ }^{1}$, and dan \\ han $^{1}$
}

${ }^{1}$ Northwest Institute of Eco-Environment and Resources

October 31, 2021

\begin{abstract}
Litter decomposition is a fundamental nutrient cycling process, and litter diversity decreases induced by biodiversity loss have substantial effects on soil carbon cycling. However, few experimental studies have characterized the effect of litter diversity on and litter chemistry. Here, we used single-species and mixed litters to study the effects of litter chemical properties on the direction, intensity and drivers of non-additive litter-mixing effects. We found that 1) there was no significant effect of litter species richness on soil processes, and the litter chemistry of component species was more robust to soil respiration and non-additive effects. 2) The early-stage mixing effect was negative, ranging from -3.1 to -0.3 , and its magnitude was strongest in chemically diverse litter mixtures; the late-stage mixing effect ranged from -2.3 to 1.3 , and the non-additive effect of chemically similar species was positive. 3) Litter carbon, lignin, phenols and soluble sugar affected early-stage soil respiration, and litter carbon, nitrogen, phenols, and condensed tannins affected late-stage soil respiration, which accounted for $46 \%$ and $56 \%$ of the variation in early- and late-stage soil respiration, respectively. 4) Compared with plant species richness, litter chemistry altered the direction and magnitude of litter mixing, and litter chemical composition (including litter chemical traits and their interactions) had a stronger effect on non-additive effects than variation in single chemical compounds according to the $\mathrm{R}^{2}$ value $\left(\mathrm{R}^{2}=0.36\right)$. 5) Artemisia halodendron, as a key sand-fixing plant species, will accelerate nutrient cycling, but it has negative effects on carbon cycling when mixed with other plant species
\end{abstract}

\section{Hosted file}

Manuscript.DOCX available at https://authorea.com/users/443796/articles/543712-interactionsamong-litter-chemical-traits-alter-the-non-additive-effect-of-litter-mixing

\section{Hosted file}

Figures.docx available at https://authorea.com/users/443796/articles/543712-interactionsamong-litter-chemical-traits-alter-the-non-additive-effect-of-litter-mixing 